\title{
Designing coaxial ground heat exchangers with a thermally enhanced outer pipe
}

\author{
Jasmin Raymond ${ }^{1 *}$, Serge Mercier ${ }^{2}$ and Luc Nguyen ${ }^{2}$
}

\author{
* Correspondence: \\ jasmin.raymond@inrs.ca \\ ${ }^{1}$ Institut national de la recherche \\ scientifique, Centre Eau Terre \\ Environnement, 490 de la \\ Couronne, Québec (Québec) G1K \\ 9A9, Canada \\ Full list of author information is \\ available at the end of the article
}

\begin{abstract}
Background: Ground heat exchangers installed in boreholes are an expensive component of a ground-coupled heat pump system, where minimizing the borehole length with appropriate materials and configuration can reduce the overall cost of the system.

Methods: Design calculations performed analytically indicate that the coaxial pipe configuration can be more advantageous than the single U-pipe configuration to reduce the total borehole length of a system.

Results: A decrease of the borehole thermal resistance and an increase of the thermal mass of water contained in the coaxial exchanger helped to reduce borehole length by up to $23 \%$ for a synthetic building load profile dominated by cooling. The decrease of the borehole thermal resistance was achieved with an outer pipe made of thermally enhanced high-density polyethylene, where the thermal conductivity is $0.7 \mathrm{~W} \mathrm{~m}^{-1} \mathrm{~K}^{-1}$.

Conclusions: The coaxial configuration requires further investigations of the technical barriers related to the installation of ground heat exchangers in the field.

Keywords: Geothermal; Heat pump; Ground heat exchanger; Borehole; Coaxial; Concentric; Pipe; Thermally enhanced
\end{abstract}

\section{定 Springer}

\section{Background}

Ground-coupled heat pump systems used for heating and cooling buildings are a highly efficient technology that takes advantage of the Earth's subsurface acting as a heat source or heat sink. The operation of heat pumps reduces the need for conventional energy. However, the systems are expensive because of the drilling or trenching required for installation of the ground heat exchangers (GHEs). Technological innovations can help reduce the length of GHEs for building energy needs to be fulfilled at lower installation cost. Reducing installation costs is particularly important for vertical systems with boreholes that tend to be more expensive than horizontal systems (Canadian GeoExchange Coalition 2010). Significant advances in addressing this market barrier can reduce the payback period of geothermal systems and increase the shares of the geothermal sector on the global heating and cooling market.

To determine the required length of vertical GHEs, one of the various parameters considered in the equation is the borehole thermal resistance (Bernier 2000), which is the ability of the GHE to resist heat transfer. Selecting appropriate materials and 
configurations to optimize the borehole thermal resistance can help decrease borehole length. To reduce the borehole thermal resistance of GHEs made with one or more Upipe, advances were made to develop space clips holding pipes separately, thermally enhanced grout (Kavanaugh and Allan 1999; Allan and Kavanaugh 1999; Carlson 2000; Borinaga-Treviño et al. 2013a, 2013b) and thermally enhanced pipe (Raymond et al. 2011a, 2011c). Further work has recently been conducted on coaxial GHEs, where the exchanger consists of two pipes imbricated into each other. The impact of the flow rate and the pipe diameter and thermal conductivity on the heat transfer rate was investigated with numerical simulations (Zanchini et al. 2010). Detailed experimental work was performed in the field to evaluate the borehole thermal resistance of different coaxial GHE configurations, where the external flow channel was made of several small pipes (Acuña et al. 2011) or a flexible liner molding the borehole wall and avoiding the use of backfill material (Acuña and Palm 2013). An analytical solution was also developed to estimate the vertical temperature distribution in the ascending and descending pipe of a coaxial GHE to improve the analysis of thermal response tests (Beier et al. 2013).

While previous research showed potential advantages of using coaxial GHEs, none of the above authors have investigated the possible bore length reduction associated with coaxial configurations. When compared to GHEs with a single or a double U-pipe that are commonly used, coaxial GHEs can contain a larger amount of water allowing greater heat storage to buffer the building peak loads. Thermally enhanced pipes made of carbon nanoparticles and high-density polyethylene (HDPE) can further reduce the borehole thermal resistance of coaxial GHEs. Design calculations were performed in this study using analytical models with the objective of evaluating the possible bore length reduction that can be achieved when using coaxial GHEs for ground-coupled heat pumps. The focus was given to pipe parameters to verify how this part of the heat exchanger can be improved. Calculations of borehole thermal resistance and heat storage capacity are initially presented to facilitate the design of coaxial GHEs. A synthetic building load profile was then used to size a ground-coupled heat pump system with either U-pipe or coaxial GHEs.

\section{Methods}

GHE materials and configurations

In Northeast America, single U-pipe GHEs are commonly installed in boreholes with a diameter and length of $152.4 \mathrm{~mm}$ (6 in.) and $152.4 \mathrm{~m}$ (500 ft; Figure 1a). Occasionally, a double U-pipe (Figure 1b) can be installed in the boreholes, but this practice seems to be more popular in Europe. The borehole is filled with thermally enhanced grout made of water, silica sand, and bentonite that has a thermal conductivity approximately equal to $1.7 \mathrm{~W} \mathrm{~m}^{-1} \mathrm{~K}^{-1}$. Again, this practice is quite common in America while this is not always the case in Europe, for example, in Sweden (Gustafsson and Westerlund 2011), where groundwater-filled boreholes are used. The pipe is made of HDPE and has a nominal diameter of $31.8 \mathrm{~mm}$ (1.25 in.). The standard dimension ratio (SDR) of the pipe is commonly 11 , which is obtained by dividing the pipe outer diameter with the pipe thickness. The thermal conductivity of the HDPE forming the pipe is assumed to be $0.4 \mathrm{~W} \mathrm{~m}^{-1} \mathrm{~K}^{-1}$. The HDPE can be mixed with carbon nanoparticles to make a thermally enhanced pipe with a thermal conductivity of $0.7 \mathrm{~W} \mathrm{~m}^{-1} \mathrm{~K}^{-1}$ (Raymond et al. 

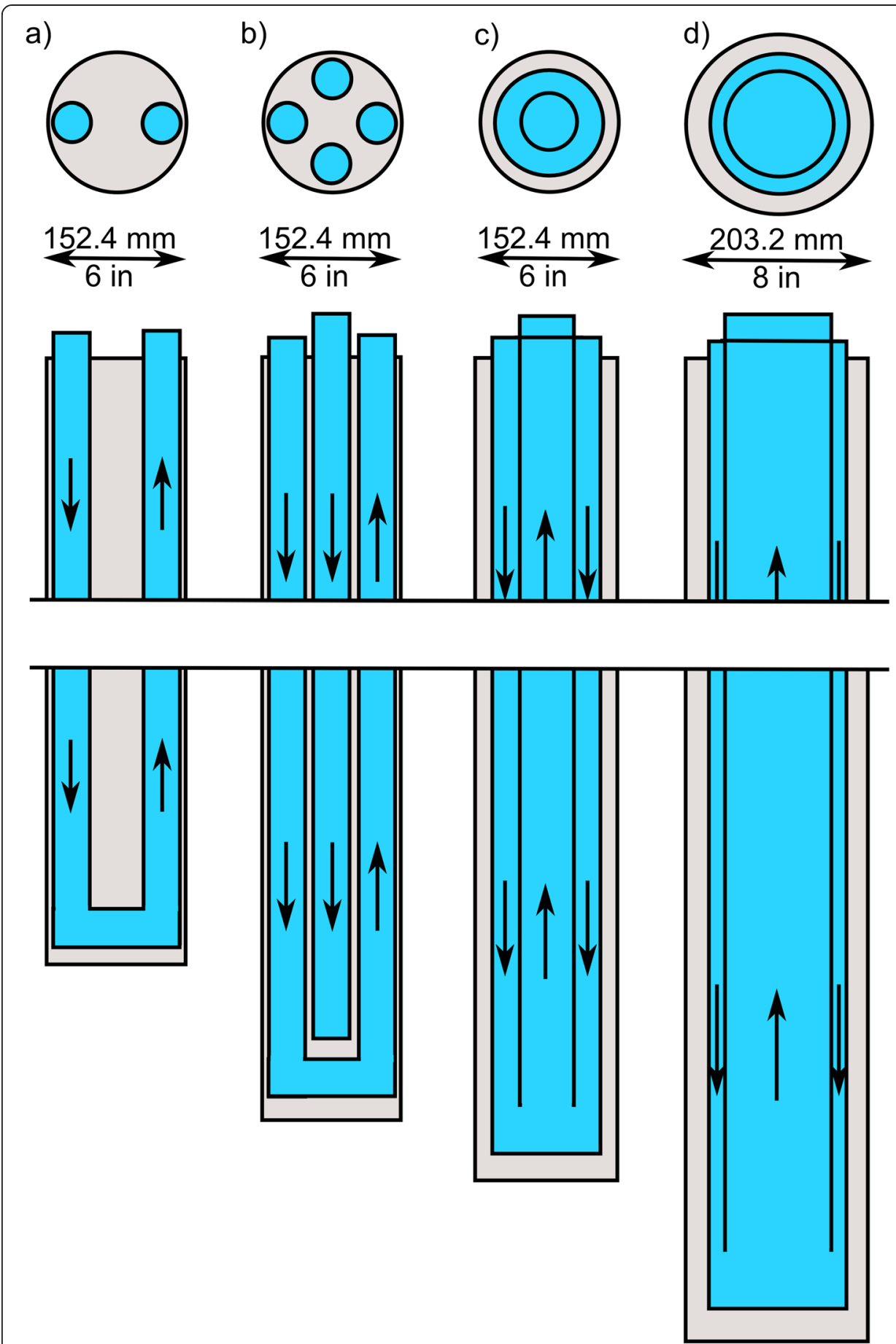

Figure 1 U-pipe (a,b) and coaxial (c,d) GHE configurations used for design calculations. The GHE length is not to scale.

2011a). Versaprofiles is the first company to commercialize such a pipe, sold under the name Geoperformx. Space clips can be used to separate the pipes from each other, reducing thermal short circuiting and consequently decreasing the borehole thermal resistance. The heat carrier fluid made of water and antifreeze enters one side of the U-pipe and exits the other at a velocity sufficient to ensure turbulent flow and facilitate heat transfer. 
The alternative coaxial design considered in this study involves the use of two pipes installed in each other to make the GHE (Figures 1c, d). Grout fills the space between the borehole wall and the outer pipe. The boreholes selected had a diameter equal to 152.4 and $203.2 \mathrm{~mm}$ (6 and 8 in.), respectively, with outer and inner pipes having a nominal diameter equal to 101.6 and $50.8 \mathrm{~mm}$ (4 and 2 in.) and 152.4 and $101.6 \mathrm{~mm}$ (6 and $4 \mathrm{in}$.). The heat carrier fluid enters the annulus and exits the inner pipe. Only pure water was selected for the heat carrier fluid to maintain a low pumping power at the higher flow rate required for turbulence to occur in the GHE annulus.

Borehole thermal resistance calculations were performed to evaluate the impact of the water flow rate, the borehole length, the backfilling material as well as the pipe thermal conductivity and SDR according to the range of parameters given in Table 1. Pure water properties were used for the heat carrier fluid. A subsurface thermal conductivity of $2.5 \mathrm{~W} \mathrm{~m}^{-1} \mathrm{~K}^{-1}$, a volumetric heat capacity of $2.5 \mathrm{MJ} \mathrm{m}^{-3} \mathrm{~K}^{-1}$, and an undisturbed temperature equal to $10^{\circ} \mathrm{C}$ were assumed for all simulations of the GHE temperature. Subsurface parameters were kept constant to verify how design parameters, especially those related to piping, can improve GHE performances.

\section{Design calculations}

The analytical approach used by the commercial programs Earth Energy Design (EED) and Ground Loop Heat Exchanger Professional (GLHEPro) were combined to properly calculate the borehole length required for a ground-coupled heat pump system with coaxial GHEs. Three-dimensional borehole thermal resistances of coaxial GHEs were initially calculated with EED according to Hellström's method (1991). The calculation includes a two-dimensional outer resistance $R_{\mathrm{b}}\left(\mathrm{m} \mathrm{K} \mathrm{W}^{-1}\right)$ determined from the flow of water in the annulus and the thermal conductivity and dimensions of the outer pipe and the backfilling material. A two-dimensional internal resistance $R_{\mathrm{a}}\left(\mathrm{m} \mathrm{K} \mathrm{W}^{-1}\right)$ is additionally determined from the flow of water in the inner pipe as well as the thermal conductivity and dimensions of the inner pipe. Both the outer and internal resistances are then used to determine an effective three-dimensional borehole thermal resistance $R_{\mathrm{b}}^{*}\left(\mathrm{~m} \mathrm{~K} \mathrm{~W}{ }^{-1}\right)$ :

$$
R_{\mathrm{b}}^{*}=R_{\mathrm{b}}\left(1+\frac{H^{2}}{3\left(\dot{m}_{\mathrm{w}} c_{\mathrm{w}}\right)^{2} R_{\mathrm{a}} R_{\mathrm{b}}}\right)
$$

where $H(\mathrm{~m})$ is the GHE length, $\dot{m}_{\mathrm{w}}\left(\mathrm{kg} \mathrm{s}^{-1}\right)$ is the mass flow rate of water circulating inside the GHE, and $c_{\mathrm{w}}\left(\mathrm{J} \mathrm{kg}^{-1} \mathrm{~K}^{-1}\right)$ is the water specific heat capacity. Equation 1

Table 1 Range of each parameter used for borehole thermal resistance calculation

\begin{tabular}{llll}
\hline Parameter & Minimum & Maximum & Average \\
\hline Water flow rate $\left(\mathrm{L} \mathrm{s}^{-1}\right)$ & 0.5 & 6 & 3.25 \\
Borehole length $(\mathrm{m})$ & 50 & 250 & 150 \\
Backfilling thermal conductivity $\left(\mathrm{W} \mathrm{m}^{-1} \mathrm{~K}^{-1}\right)$ & 0.6 & 2.8 & 1.7 \\
Pipe thermal conductivity $\left(\mathrm{W} \mathrm{m} \mathrm{m}^{-1} \mathrm{~K}^{-1}\right)$ & 0.1 & 0.7 & 0.4 \\
Pipe outside diameter (mm)/thickness $(\mathrm{mm})$ & SDR-11 & SDR-17 & SDR-13.5 \\
31.75-mm (1.25 in.) nominal diameter & $42.0 / 3.8$ & Not used for U-pipe & Not used for U-pipe \\
50.8-mm (2 in.) nominal diameter & $59.7 / 5.5$ & $60.3 / 3.6$ & $59.8 / 4.5$ \\
101.6-mm (4 in.) nominal diameter & $113.1 / 10.4$ & $114.3 / 6.7$ & $113.3 / 8.5$ \\
152.4-mm (6 in.) nominal diameter & $166.4 / 15.3$ & $168.3 / 9.9$ & $166.8 / 12.5$ \\
\hline
\end{tabular}


assumes a constant heat injection rate along the borehole depth, which is convenient but departs from field observations (Beier et al. 2013). Using Hellström's method (1991) implemented in EED, it is possible to take into account the internal resistance, which can be significant for long boreholes typically drilled for coaxial GHEs. Calculating borehole thermal resistances with the program GLHEPro involves a two-dimensional approach that would not be suitable for determining the impact of increasing the borehole length or insulating the inner pipe.

Effective three-dimensional borehole thermal resistances of GHEs with a single and a double U-pipe were also calculated with Equation 1 and compared with the resistances of coaxial GHEs. In that case, the two-dimensional borehole thermal resistance was determined using the multipole method, with recent improvements about boundary conditions (Claesson and Hellström 2011).

For sizing and simulation purposes, the average water temperature $\bar{T}_{\mathrm{w}}\left({ }^{\circ} \mathrm{C}\right)$ inside the GHEs was calculated with GLHEPRO:

$$
\bar{T}_{\mathrm{w}}=T_{\mathrm{s}}-q R_{\mathrm{b}}^{*}-\frac{q}{2 \pi k_{\mathrm{s}}} g\left(\frac{t}{t_{\mathrm{sc}}}, \frac{r_{\mathrm{b}}}{H}\right)
$$

where $T_{\mathrm{s}}\left({ }^{\circ} \mathrm{C}\right)$ is the undisturbed temperature of the subsurface, $q\left(\mathrm{~W} \mathrm{~m}^{-1}\right)$ is the heat transfer rate per unit length of GHE, $k_{\mathrm{s}}$ is the subsurface thermal conductivity $\left(\mathrm{W} \mathrm{m}^{-1} \mathrm{~K}^{-1}\right), t_{\mathrm{sc}}$ $\left(\mathrm{s} ; t_{\mathrm{sc}}=H^{2} / 9 \alpha_{\mathrm{s}}\right)$ is the time scale, and $r_{\mathrm{b}}(\mathrm{m})$ is the borehole radius. When normalizing the time with the time scale, $\alpha_{\mathrm{s}}\left(\mathrm{m}^{2} \mathrm{~s}^{-1}\right)$ is the subsurface thermal diffusivity. The superposition principle takes into account temporal variations of the heat transfer rate calculated from monthly and peak building loads as well as the heat pump coefficient of performance affected by the water temperature leaving the GHEs. The longterm response of the GHE field is defined according to (Eskilson 1987) $g(-)$ function, whose short-term response has been modified to consider the effect of the thermal mass of water contained in the system (Xu and Spitler 2006). When sizing and simulating GHEs, temperatures computed with GLHEPRO are affected by heat stored inside the water contained in the GHEs and all surface piping, an approach that is neglected with EED. Temperature changes due to short-term peak loads can be damped by the thermal mass of water, especially for coaxial GHEs that contain a greater amount of water than single and double U-pipe GHEs. An adequate approach for coaxial GHE design was to manually calculate the borehole thermal resistance affected by internal heat transfer with EED, and then specifying that value in GLHEPRO in an iterative manner for sizing and simulation, accounting for the thermal mass of water.

After sizing and simulating a ground-coupled heat pump system with various GHE configurations, the pumping power was calculated for U-pipe and coaxial GHEs and compared to one another. The Darcy-Weisbach equation was used to calculate head loss through piping under a worst-case scenario, i.e., when the viscosity of water is higher at lower temperatures. Those conditions are expected during each heating season when the GHEs are use to extract energy from the subsurface and the water temperature in the GHEs decreases. The pumping power was then calculated by multiplying the water flow rate and density, the gravitational acceleration and the head loss through all the GHEs. 


\section{Results and discussion}

\section{Sensitivity of design parameters to the borehole thermal resistance}

The 3D borehole thermal resistance of coaxial GHEs with a borehole diameter of 152.4 and $203.2 \mathrm{~mm}$ (6 and $8 \mathrm{in}$.) was calculated with EED using average values of the parameters given in Table 1. GHE parameters were then varied one at a time to evaluate the impact of changing the water flow rate, the borehole length, the thermal conductivity of the backfilling, and the inner and outer pipe materials as well as the inner and outer pipe SDR (Figure 2). The minimum and maximum values given in Table 1 were used to assess the sensitivity of each parameter. Increasing the flow rate reduced the borehole thermal resistance by up to $35 \%$, with most variations when flow in the outer annulus changes from laminar to turbulent (Figure 2a). Increasing the borehole length from 50 to $250 \mathrm{~m}$ increased the borehole thermal resistance by about $2 \%$ (Figure $2 \mathrm{~b}$ ). This variation is due to the three-dimensional approach used with Equation 1 to evaluate internal heat transfer effects for the borehole thermal resistance and that, unlike methods limited by two dimensions, takes into account the borehole length at the numerator. Varying the thermal conductivity of the backfilling material changed the borehole thermal resistance by up to $41 \%$ (Figure 2c). Using a material having a thermal conductivity lower than that of HDPE for the inner pipe had a negligible impact of $0.6 \%$ on the borehole thermal resistance. However, increasing the outer pipe thermal conductivity reduced the borehole thermal resistance by up to $32 \%$ (Figures 2d, e). Similarly, changing the SDR of the inner pipe had little impact, while increasing the SDR of the outer pipe reduced the borehole thermal resistance by up to $32 \%$ (Figures $2 \mathrm{f}, \mathrm{g}$ ). In summary, calculations for coaxial GHEs indicate negligible advantages associated with insulating the inner pipe. Considerable advantages were obtained by increasing the water flow rate, the thermal conductivity of the outer pipe and the backfilling material as well as the outer pipe SDR. The main effect of increasing the outer pipe SDR is a reduce pipe thickness.

Borehole thermal resistance for single and double U-pipe GHEs was calculated with average parameters given in Table 1 for an SDR-11 pipe having a nominal diameter of $31.8 \mathrm{~mm}$ (1.25 in.). The spacing between the centers of the two sides of a U-pipe was $100 \mathrm{~mm}$ to be representative of a case with space clips that are commonly used. Both regular and thermally enhanced HDPE pipes of thermal conductivity equal to 0.4 and $0.7 \mathrm{~W} \mathrm{~m}^{-1} \mathrm{~K}^{-1}$ were considered and used as reference cases. Obtained resistances were compared to those calculated for coaxial GHEs using average parameters (Table 1), except for the outer pipe thermal conductivity and SDRs that were increased. Coaxial GHEs had resistances up to $55 \%$ smaller than those of single U-pipe GHEs when increasing the outer pipe thermal conductivity or SDR (Figures 3a, b). Coaxial GHEs resistances were however higher than the double U-pipe GHEs considered in this study. The lowest resistance obtain with the coaxial configuration was about $22 \%$ higher than the resistance of the double U-pipe GHE made with thermally enhanced HDPE. In summary, it was necessary to improve the outer pipe material and dimensions of the coaxial GHE for its resistance to be smaller than the single U-pipe GHE, and it was not possible to have a resistance significantly smaller than the double U-pipe GHE.

\section{Thermal mass of water in the GHEs}

The volume of water contained in a GHE that is $150 \mathrm{~m}$ long was calculated for four scenarios. The first two calculations were for a single and a double U-pipe GHE, whose 

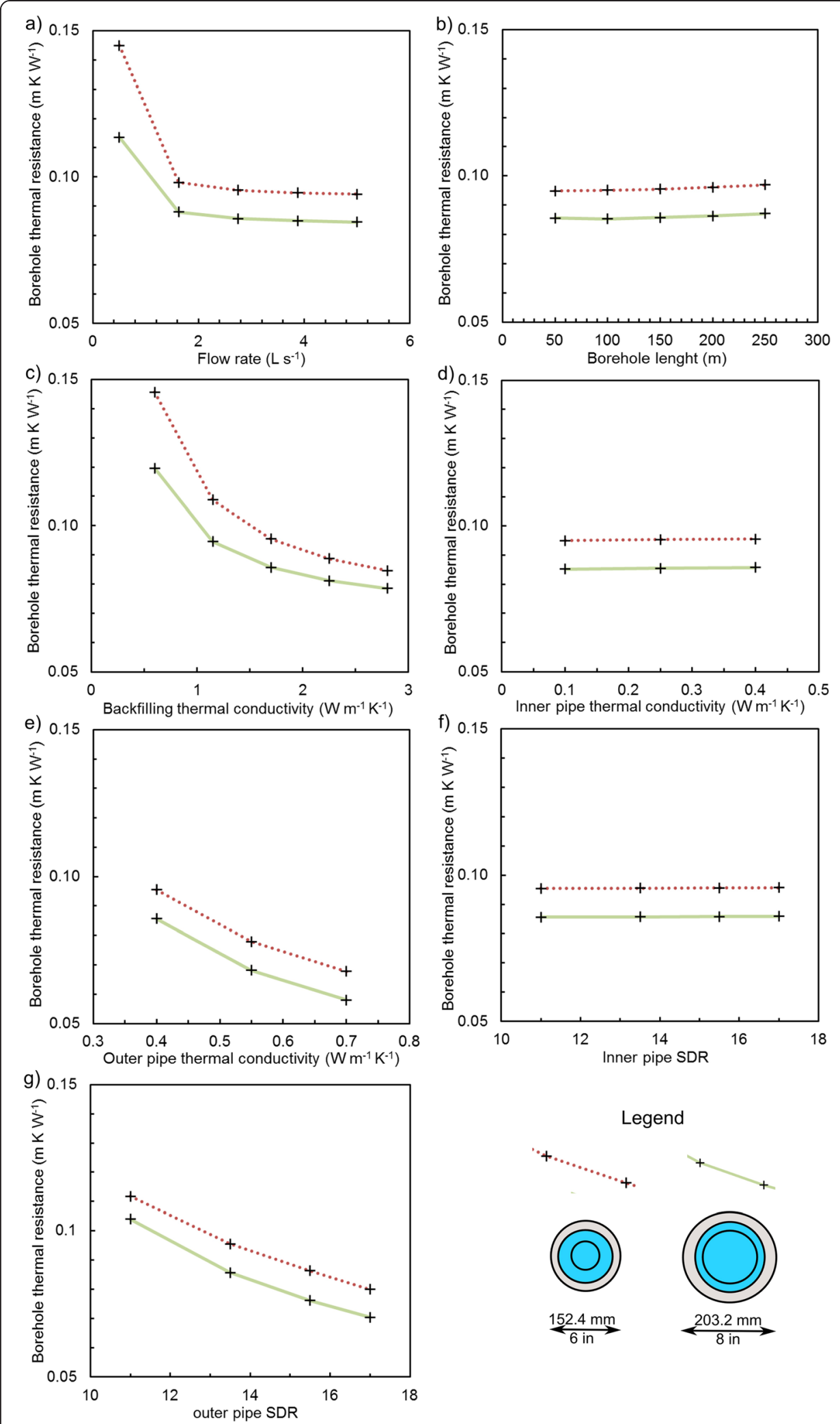

Figure 2 Borehole thermal resistance of coaxial GHEs. The GHE configuration belonging to each graphic line is shown in the legend with a cross section sketch of the pipes and borehole. 


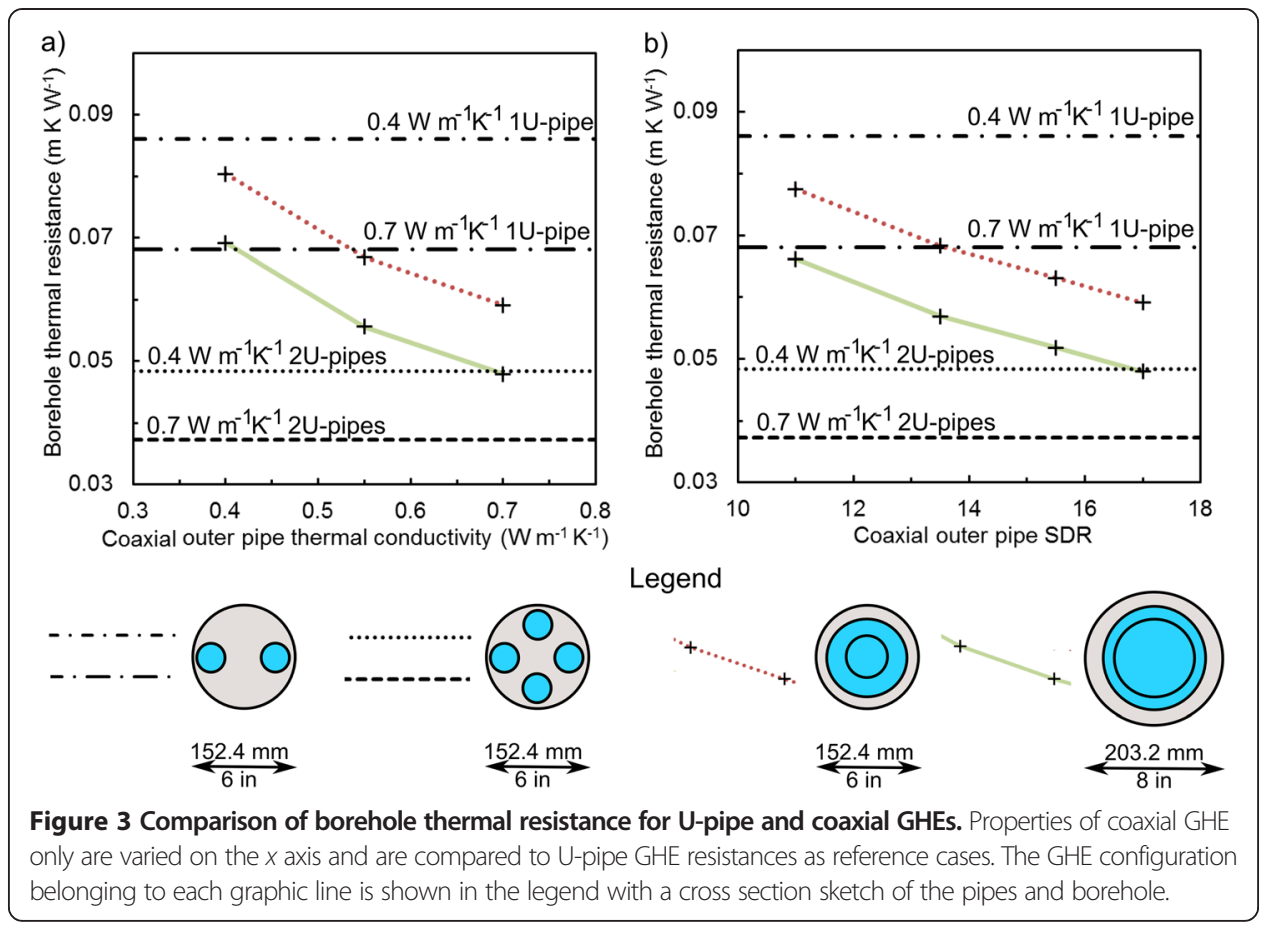

pipe nominal diameter is $31.8 \mathrm{~mm}$ (1.25 in.). In the third and fourth cases, the volume of water was calculated for coaxial GHEs, where the outer and inner pipes have nominal diameters of 101.6 and $50.8 \mathrm{~mm}$ (4 and $2 \mathrm{in}$.) and 152.4 and $101.6 \mathrm{~mm}$ (6 and 4 in.), respectively. The water volume was then multiplied by the volumetric heat capacity of water $\left(4.2 \mathrm{MJ} \mathrm{m}^{-3} \mathrm{~K}^{-1}\right)$ to determine the amount of energy needed to increase the temperature of water in the GHE by $1 \mathrm{~K}$. When comparing the U-pipe versus the coaxial cases, the amount of energy was shown to be 6 to 28 times smaller (Figure 4). The increase of heat storage capacity associated with coaxial GHEs is expected to positively impact sizing calculations performed with GLHEPRO, where the fluid factor has been set to 1 for all cases presented below. The fluid factor in GLHEPRO is the ratio of the total fluid in the system to the fluid in the GHE. Since the amount of water in surface piping is expected to be similar, a value equal to 1 was used to compare each case, which neglected the water in the near surface piping connecting all of the GHEs together.

\section{Sizing and simulation of a ground-coupled heat pump system}

A synthetic building load profile was generated over a full year with a sinusoidal function for the sizing and simulation of a fictive ground-coupled heat pump system. The function was used to generate the fictitious hourly loads $Q_{b l}$ (W; Bernier 2000):

$$
Q_{\mathrm{bl}}=A+B \sin \left(270+\frac{h_{\mathrm{y}}}{8,760} 360\right) \times \sin \left(\frac{h_{\mathrm{d}}}{24} 180\right)
$$

used as inputs for the sizing calculations. In Equation 3, $A$ and $B$ are constants that have been set to 50 and $100 \mathrm{~kW}$, respectively. The arguments of the sin functions are in degrees, and $h_{\mathrm{y}}$ and $h_{\mathrm{d}}$ are the hours of the year $(0$ to 8,760$)$ and day (0 to 24$)$, respectively. The resulting load profile was cooling dominated, with a peak cooling load of $-150 \mathrm{~kW}$ occurring in July and a peak heating load of $50 \mathrm{~kW}$ occurring in January 


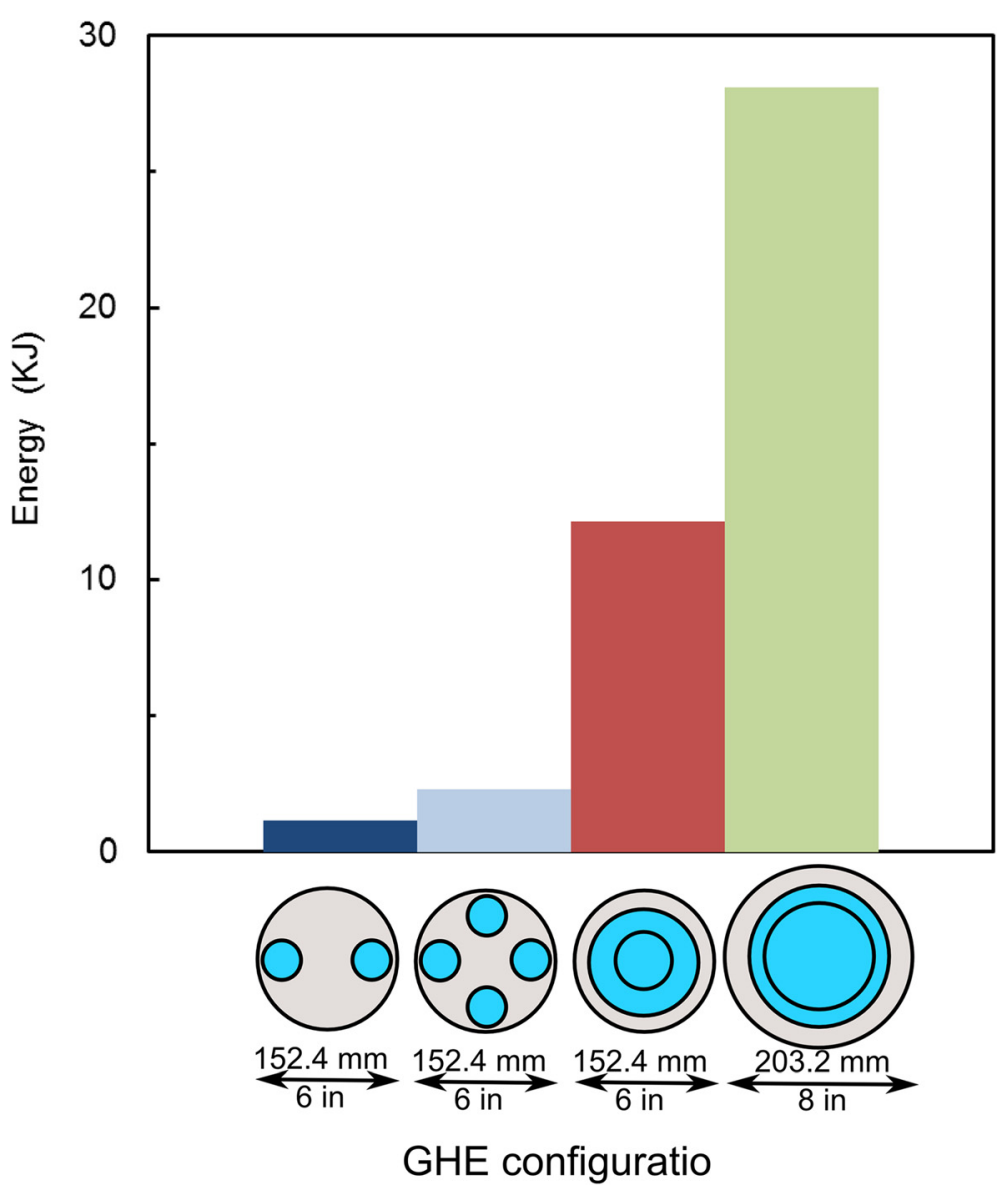

Figure 4 Energy required to increase the water temperature inside GHEs by $1 \mathrm{~K}$. The GHE configuration belonging to each graphic line is shown in the legend with a cross section sketch of the pipes and borehole.

(Figure 5). The choice of negative sign for cooling loads is to express heat rejected toward the subsurface. Daily peak loads were maintained for approximately $3 \mathrm{~h}$. This choice of load profile is arbitrary and intended to require more cooling since cooling dominated buildings appear to be better suited for coaxial GHEs using pure water for the heat carrier fluid. The purpose was to investigate conditions where coaxial GHE could potentially be successful. Such scenario was also advantageous for double U-pipe GHEs that can be operated at a low flow rate when using pure water for the heat carrier fluid. Cooling-dominated profiles are additionally common to commercial buildings with internal gains found in Northeast America. The system was consequently sized according to the peak cooling loads and water temperature in GHEs remained above freezing. Antifreeze solutions such as propylene glycol used in GHEs operating below freezing conditions for heating dominated buildings increase the fluid viscosity and the flow rate needed for turbulence in coaxial GHEs. Designing a system with coaxial GHEs for a heating-dominated building is not impossible. For example, a calcium chloride solution of low viscosity with intermediate plate heat exchangers may be used but can be more complicated. This aspect is handled more easily with single U-pipe GHEs having a smaller pipe cross section and where fluid turbulence is reached at reasonable flow rates.

GHE fields for all sizing and simulation cases were rectangular. Boreholes were added when greater GHE length was needed, and the distance between each borehole was 


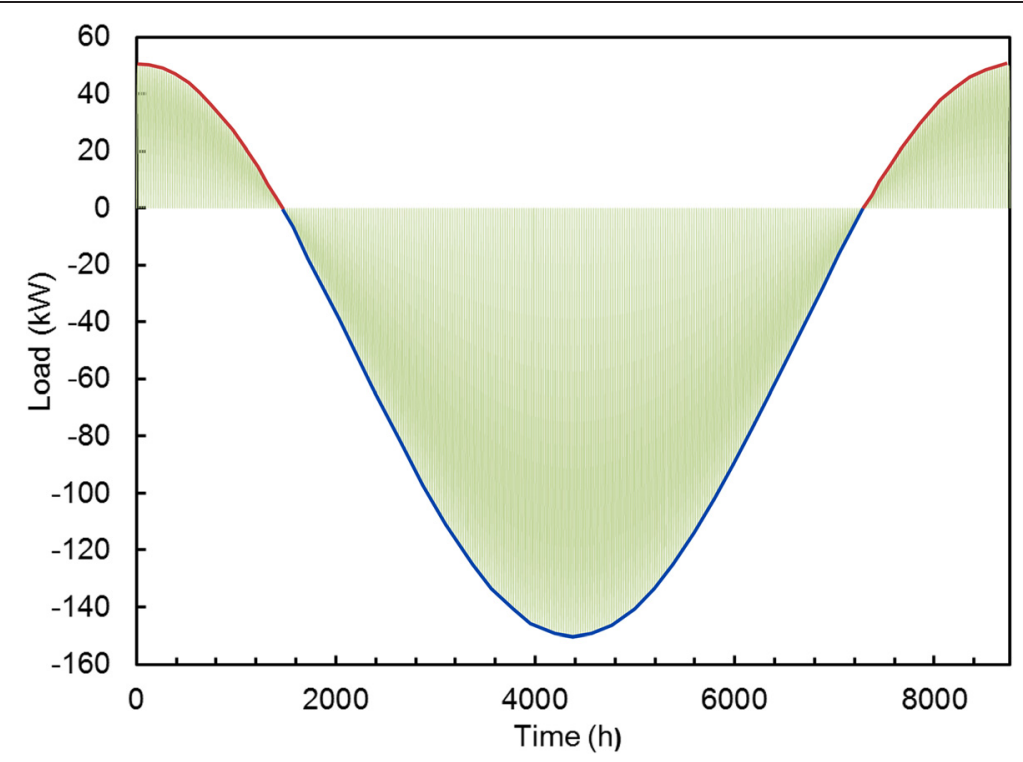

Figure 5 Synthetic load profile used for design calculations.

kept at $10 \mathrm{~m}$ to minimize thermal interaction between GHEs. The target depth of the boreholes for cases with single U-pipe GHEs was approximately $150 \mathrm{~m}$, whereas those for cases with double U-pipe and coaxial GHEs were from 180 to $250 \mathrm{~m}$. A greater depth is necessary with double U-pipe and coaxial GHEs for a system to have fewer boreholes such that the total system flow rate remains reasonably low. This ensures that the flow rate of individual GHEs is high and turbulent, even in the larger pipe of the coaxial GHEs. Balancing flow rates to minimize total system flow and maximize individual GHE flow is a key for designing coaxial GHEs that can be achieved by drilling to greater depths. Six cases with different U-pipe and coaxial GHEs were selected for the sizing calculations (Table 2). The maximum water temperature chosen to enter the heat pump system during the peak cooling condition was $35^{\circ} \mathrm{C}$. For the water temperature to fulfill this criterion during a 10-year period, sizing was initially performed when the full building loads were applied to the GHE field. A second round of sizing calculations was carried out using the same duration for a hybrid system that encloses a cooling tower with $55 \mathrm{~kW}$ of cooling capacity, approximately one third of the peak cooling load.

The sizing calculations indicated that reducing borehole thermal resistance and increasing water volume for the coaxial GHEs helped to decrease the total borehole length by $9 \%$ to $23 \%$ (Table 2). This compares to a $5 \%$ to $20 \%$ bore length reduction when using thermally enhanced HDPE with a single U-pipe, double U-pipe, or a combination of both. The bore length reduction for the single U-pipe GHEs with thermally enhanced HDPE can be more than $8 \%$ when the subsurface thermal conductivity is $4.5 \mathrm{~W} \mathrm{~m}^{-1} \mathrm{~K}^{-1}$ or higher (Raymond et al. 2011a). The subsurface thermal conductivity at the borehole interface, considered when using the multipole method (Claesson and Hellström 2011) to calculate the borehole thermal resistance of U-pipe GHEs, has a small effect on the resistance. This is due to the non-uniform temperature distribution at the borehole interface of U-pipe GHEs (Lamarche et al. 2010; Raymond et al. 2011b). A uniform temperature can be assumed for coaxial GHEs at the borehole 
Table 2 GHE configuration and sizing calculation results for the synthetic load profile

\begin{tabular}{|c|c|c|c|c|c|c|}
\hline \multicolumn{7}{|l|}{ GHE configuration } \\
\hline Borehole diameter - mm (in.) & $152.4(6)$ & $152.4(6)$ & $152.4(6)$ & $152.4(6)$ & $152.4(6)$ & $203.2(8)$ \\
\hline GHE configuration & 1 U-pipe & 1 U-pipe & 2 U-pipe & 2 U-pipe & Coaxial & Coaxial \\
\hline \multirow[t]{2}{*}{ Pipe nominal diameter - mm (in.) } & $31.8(1.25)$ & $31.8(1.25)$ & $31.8(1.25)$ & $31.8(1.25)$ & $\begin{array}{l}101.6(4) \\
\text { outer }\end{array}$ & $\begin{array}{l}152.4(6) \\
\text { outer }\end{array}$ \\
\hline & & & & & $\begin{array}{l}50.8(2) \\
\text { inner }\end{array}$ & $\begin{array}{l}101.6(4) \\
\text { inner }\end{array}$ \\
\hline \multirow[t]{2}{*}{ Pipe SDR } & 11 & 11 & 11 & 11 & 17 outer & 17 outer \\
\hline & & & & & 11 inner & 11 inner \\
\hline \multirow[t]{2}{*}{ Pipe thermal conductivity - $\mathrm{W} \mathrm{m}^{-1} \mathrm{~K}^{-1}$} & 0.4 & 0.7 & 0.4 & 0.7 & 0.7 outer & 0.7 outer \\
\hline & & & & & 0.4 inner & 0.4 inner \\
\hline Grout thermal conductivity - $\mathrm{W} \mathrm{m}^{-1} \mathrm{~K}^{-1}$ & 1.7 & 1.7 & 1.7 & 1.7 & 1.7 & 1.7 \\
\hline \multicolumn{7}{|l|}{$\begin{array}{l}\text { Sizing calculation results when applying } \\
\text { the full building loads }\end{array}$} \\
\hline Total flow rate $-L s^{-1}$ & 7 & 7 & 7 & 7 & 9.6 & 8 \\
\hline Borehole thermal resistance - $\mathrm{m} \mathrm{KW}^{-1}$ & 0.0955 & 0.0777 & 0.0563 & 0.0443 & 0.0734 & 0.0630 \\
\hline GHE grid & $4 \times 4$ & $4 \times 4$ & $3 \times 4$ & $2 \times 5$ & $3 \times 4$ & $2 \times 4$ \\
\hline Individual GHE length - m & 159 & 151 & 181 & 203 & 194 & 246 \\
\hline Total GHE length - m & 2,544 & 2,416 & 2,172 & 2,030 & 2,328 & 1,968 \\
\hline Total water volume in GHE - $\mathrm{m}^{3}$ & 4.62 & 4.39 & 7.89 & 7.37 & 16.43 & 27.48 \\
\hline Pumping power for peak conditions - W & 246 & 234 & 138 & 213 & 130 & 31 \\
\hline Borehole length reduction - \% & - & 5 & 15 & 20 & 9 & 23 \\
\hline \multicolumn{7}{|l|}{$\begin{array}{l}\text { Sizing calculation results for a hybrid } \\
\text { system with a } 55-\mathrm{kW} \text { cooling tower }\end{array}$} \\
\hline Total flow rate $-L s^{-1}$ & 4.6 & 4.6 & 4.6 & 4.6 & 6 & 6 \\
\hline Borehole thermal resistance - $\mathrm{m} \mathrm{KW}^{-1}$ & 0.0948 & 0.0768 & 0.0547 & 0.0442 & 0.0701 & 0.0587 \\
\hline GHE grid & $2 \times 5$ & $2 \times 5$ & $2 \times 4$ & $2 \times 3$ & $2 \times 3$ & $2 \times 3$ \\
\hline Individual GHE length - m & 146 & 137 & 158 & 199 & 222 & 198 \\
\hline Total GHE length - m & 1,460 & 1,370 & 1,264 & 1,194 & 1,332 & 1,188 \\
\hline Total water volume in GHE - $\mathrm{m}^{3}$ & 2.65 & 2.49 & 4.59 & 4.37 & 9.40 & 16.59 \\
\hline Pumping power for peak conditions - W & 160 & 152 & 77 & 160 & 137 & 19 \\
\hline Borehole length reduction - \% & - & 6 & 13 & 18 & 9 & 19 \\
\hline
\end{tabular}

interface in the case of homogenous subsurface because of the GHE axial symmetry. Calculation of the borehole thermal resistance for the coaxial GHE is therefore independent of the subsurface thermal conductivity. A constant value of $2.5 \mathrm{~W} \mathrm{~m}{ }^{-1} \mathrm{~K}^{-1}$ was consequently used for the subsurface thermal conductivity in the current study. The coaxial GHEs with a borehole diameter of $203.2 \mathrm{~mm}$ (8 in.) were the most efficient configuration to reduce the total borehole length. The total system flow rate had to be increased for the coaxial GHEs to have a low borehole thermal resistance. Although higher flow rates were used, the pumping power associated with the coaxial GHEs remained lower because of the larger flow channels. The maximum temperature that entered the heat pump occurred at month 115 for the design cases using coaxial GHEs with a borehole diameter of $203.2 \mathrm{~mm}$ (8 in.; Figure 6). Other design cases showed a similar temperature evolution of the water in the GHEs and are not included on the graph to avoid repetition. 


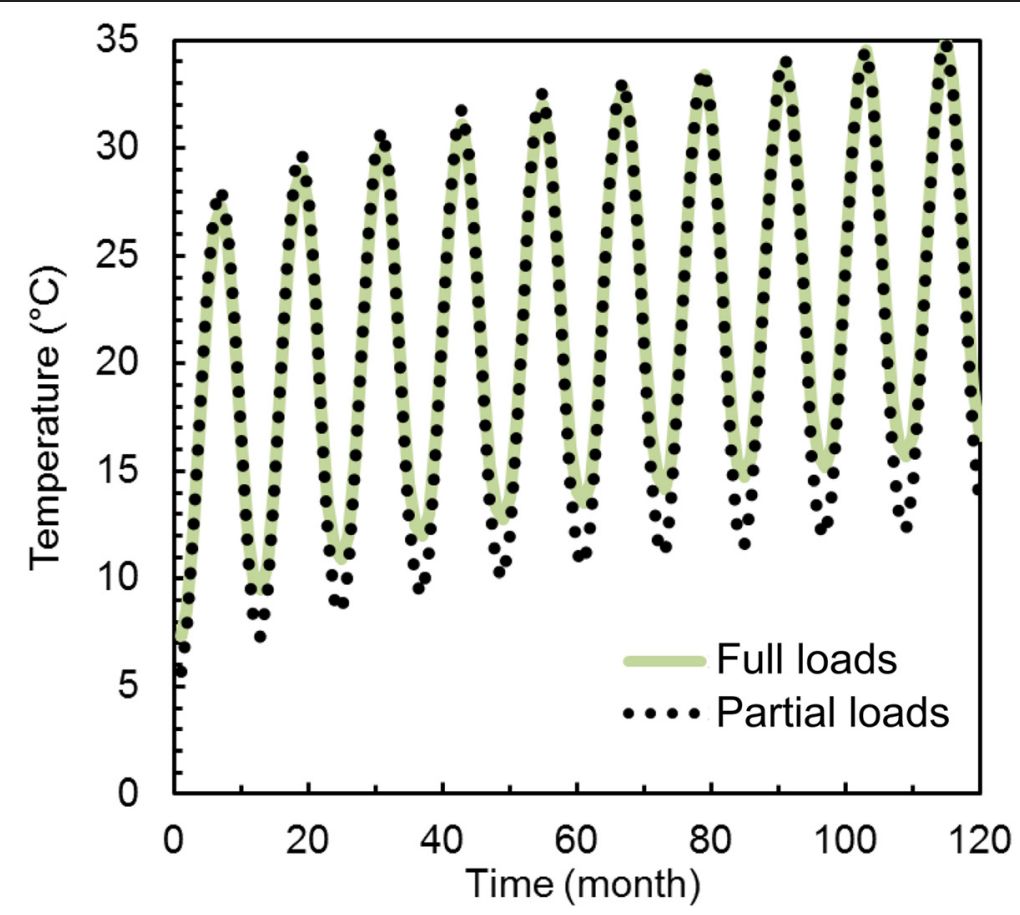

Figure 6 Maximum fluid temperature entering the heat pump for a system using coaxial GHEs.

Borehole diameter is $203.2 \mathrm{~mm}$ (8 in.).

\section{Conclusions}

Design calculations performed for a fictive ground-coupled heat pump system using a synthetic load profile demonstrated that coaxial GHEs can reduce the total borehole length required for the system to fulfill a building's energy needs. Boreholes of coaxial GHEs studied in this manuscript had a diameter of 152.4 and $203.2 \mathrm{~mm}$ (6 and 8 in.) and have been compared with single and double U-pipe GHEs with a borehole diameter of $152.4 \mathrm{~mm}$ ( 6 in.). The parameters that needed to be improved for the coaxial GHEs to result in less total borehole length were the water flow rate as well as the outer pipe thermal conductivity and dimensions. It was helpful to select a thermally enhanced pipe made of HDPE with a thermal conductivity of $0.7 \mathrm{~W} \mathrm{~m}^{-1} \mathrm{~K}^{-1}$ and with a standard dimension ratio equal to 17 to form the outer flow channel of coaxial GHEs. Calculations suggested that at a high flow rate, the borehole thermal resistance of the proposed coaxial GHEs can be below $0.05 \mathrm{~m} \mathrm{~K} \mathrm{~W}^{-1}$, which is significantly below single U-pipe GHEs but remains above double U-pipe GHEs. Another possible configuration to reduce the borehole thermal resistance is a coaxial GHE made with a flexible liner (Acuña and Palm 2013), which was shown to have a measured resistance that is $40 \%$ smaller than the lowest resistance of coaxial GHE considered in this study. Insulating the inner pipe with materials of thermal conductivity lower than that of HDPE had a negligible effect on the borehole thermal resistance reported in this study. Thermal short-circuiting between the inner and outer flow channel was not a major concern for the studied GHEs with a large diameter, which can be different for GHEs of small diameter (Zanchini et al. 2010). The volume of water in the proposed coaxial GHEs was up to 28 times greater than the volume for U-pipe GHEs, which is a second factor explaining the borehole length reduction. The large coaxial GHEs with a high heat 
storage capacity provided more bore length reduction than the double U-pipe GHEs even though the borehole thermal resistance was higher.

Sizing calculations considered the internal borehole thermal resistance (Hellström 1991) and the thermal mass of water (Xu and Spitler 2006) of the coaxial GHEs and enthusiastically revealed borehole length reductions of up to $23 \%$. However, technical barriers still have to be addressed for those reductions to provide savings on installation costs. The coaxial GHEs with a borehole diameter of $203.2 \mathrm{~mm}(8 \mathrm{in}$.) showed most advantages associated with borehole thermal resistance and heat storage capacity. Commercial drilling capacity available in North America may need to accommodate larger boreholes for coaxial GHEs to be installed at competitive cost. Assembling HDPE pipes with a large diameter can complicate the installation process because large pipes are commonly shipped in sections to be joined with fusion tools in the field. The double U-pipe GHEs were shown to provide slightly smaller but similar advantages for the total borehole length reduction (up to $20 \%$ ), especially when considering thermally enhanced pipe and deeper boreholes. While efficient technology to install coaxial GHEs may not be available at the moment, installation of double U-pipe GHE can be achieved with current tools and expertise. The drilling depth is an important factor for balancing flow rate of both double U-pipe and coaxial GHEs. Determining the depth at which this practice remains economical would require further research. In any cases, the thermally enhanced pipe was shown to be an asset for the alternative GHE configurations studied.

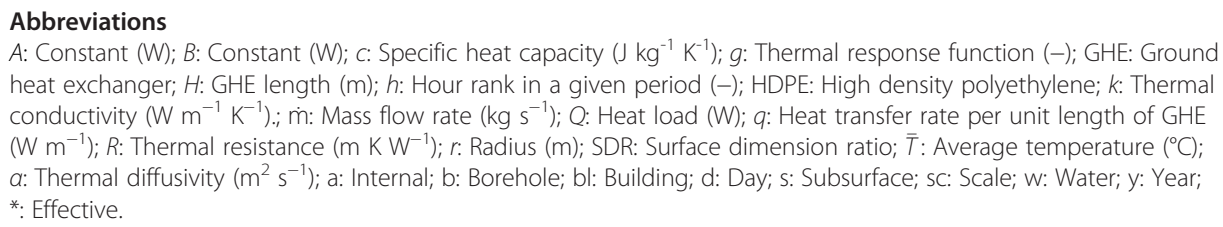

The first author of this manuscript has no competing interests. The second and third authors of this manuscript are working for Versaprofiles that produce thermally enhanced pipes for ground-coupled heat pump systems.

\section{Authors' contributions}

The researcher JR performed the calculations and wrote the manuscript under the support and guidance of pipe industry specialists SM and LN to make results useful for practitioners. All authors read and approved the final manuscript.

\section{Acknowledgements}

Professor Jeffrey Spitler at Oklahoma State University is kindly acknowledged for providing the program GLHEPRO to conduct the work presented in this manuscript. The comments of two anonymous reviewers were appreciated to improve this manuscript.

\section{Author details}

${ }^{1}$ Institut national de la recherche scientifique, Centre Eau Terre Environnement, 490 de la Couronne, Québec (Québec) G1K 9A9, Canada. ${ }^{2}$ Versaprofiles, 130 rue Aubé, Saint-Lazare-de-Bellechasse, (Québec) G0R 3J0, Canada.

Received: 7 November 2014 Accepted: 17 March 2015

Published online: 08 April 2015

References

Acuña J, Mogensen P, Palm B (2011) Distributed thermal response tests on a multi-pipe coaxial borehole heat exchanger. HVAC \& R Research 17:1012-1029

Acuña J, Palm B (2013) Distributed thermal response tests on pipe-in-pipe borehole heat exchangers. Appl Energy 109:312-320

Allan ML, Kavanaugh SP (1999) Thermal conductivity of cementitious grouts and impact on heat exchange length design for ground source heat pumps. HVAC \& R Research 5:87-98

Beier RA, Acuña J, Mogensen P, Palm B (2013) Borehole resistance and vertical temperature profiles in coaxial borehole heat exchangers. Appl Energy 102:665-675 
Bernier M (2000) A review of the cylindrical heat source method for the design and analysis of vertical ground-coupled heat pump systems. In: Proceedings of the fourth International conference on heat pumps in cold climates, Caneta Research Inc., Aylmer, Canada.

Borinaga-Treviño R, Pascual-Muñoz P, Castro-Fresno D, Blanco-Fernandez E (2013a) Borehole thermal response and thermal resistance of four different grouting materials measured with a TRT. Appl Therm Eng 53:13-20

Borinaga-Treviño R, Pascual-Muñoz P, Castro-Fresno D, Del Coz-Díaz JJ (2013b) Study of different grouting materials used in vertical geothermal closed-loop heat exchangers. Appl Therm Eng 50:159-167

Canadian GeoExchange Coalition (2010) The state of the Canadian geothermal heat pump industry 2010 - industry survey and market analysis. Public Report, Canadian GeoExchange Coalition, Montreal, Canada, http://www.geo-exchange.ca/ en/UserAttachments/article64_Industry\%20Survey\%202010_FINAL_E.pdf. Accessed November 3rd, 2014

Carlson SW (2000) GSHP bore field performance comparisons of standard and thermally enhanced grout. ASHRAE Trans 106:442-446

Claesson J, Hellström G (2011) Multipole method to calculate borehole thermal resistances in a borehole heat exchanger. HVAC \& R Research 17:895-911

Eskilson P (1987) Thermal analysis of heat extraction boreholes. Ph. D Thesis, Lund Institute of Technology, Department of mathematical physics, Lund, Sweden

Gustafsson A-M, Westerlund L (2011) Heat extraction thermal response test in a groundwater-filled borehole heat exchanger - Investigation of the borehole thermal resistance. Renew Energy 36:2388-2394

Hellström G (1991) Ground heat storage; thermal analysis of duct storage systems. Ph. D. thesis, University of Lund, Department of mathematical physics, Lund, Sweden

Kavanaugh SP, Allan ML (1999) Testing of thermally enhanced cement ground heat exchangers grout. ASHRAE Trans 105:446-450

Lamarche L, Kajl S, Beauchamp B (2010) A review of methods to evaluate borehole thermal resistances in geothermal heat-pump systems. Geothermics 39:187-200

Raymond J, Frenette M, Léger A, Magni E, Therrien R (2011a) Numerical modeling of thermally enhanced pipe performances in vertical ground heat exchangers. ASHRAE Trans 117:899-907

Raymond J, Therrien R, Gosselin L (2011b) Borehole temperature evolution during thermal response tests. Geothermics 40:69-78

Raymond J, Therrien R, Gosselin L, Lefebvre R (2011c) A review of thermal response test analysis using pumping test concepts. Ground Water 49:932-945

Xu X, Spitler J D (2006) Modeling of vertical ground loop heat exchangers with variable convective resistance and thermal mass of the fluid. In: Proceedings of the 10th international conference on thermal energy storage, Ecostock, Ponoma NJ: The Richard Stockton College of New Jersey

Zanchini E, Lazzari S, Priarone A (2010) Improving the thermal performance of coaxial borehole heat exchangers. Energy 35:657-666

\section{Submit your manuscript to a SpringerOpen ${ }^{\circ}$ journal and benefit from:}

- Convenient online submission

- Rigorous peer review

- Immediate publication on acceptance

- Open access: articles freely available online

- High visibility within the field

- Retaining the copyright to your article 